\title{
NON-UNIFORM ONSET OF NUCLEATE FLOW BOILING OF R-134A INSIDE A GLASS MINICHANNEL
}

\author{
Chiara Baldassari, Mauro Mameli, Marco Marengo ${ }^{1}$ \\ Department of Engineering, University of Bergamo, Viale Marconi 5, Dalmine (BG), 24044 \\ Italy, marco.marengo@unibg.it, Ph.+39 0352052002, Fax +390352052077
}

\section{KEYWORDS}

Flow boiling, onset nucleate boiling, flow pattern, HFC134a refrigerant

\section{ABSTRACT}

Even if far from being completely characterized, convective boiling inside mini- and microchannels is likely to be one of the most relevant process for enhancing the cooling capability of modern heat transfer devices. Since, due to the process miniaturization, many novel devices are very small, fully developed flows are difficult to achieve, and therefore the knowledge of the onset nucleate boiling (ONB) position is even more critical for cooling design. However visualization of the ONB phenomena is not common in the literature, since usually the heaters are made in opaque metals and therefore they are not allowing a complete imagining. The present work consists in an experimental investigation of the incipient boiling of R134a inside a circular glass mini-channel mounted horizontally and equipped with a series of transparent Indium Tin Oxide (ITO) heaters. The effects of the heat flux input levels and the refrigerant mass fluxes on the ONB process and on the saturated boiling heat transfer rate are quantitatively explored. The flow pattern visualizations, carried on by means of a highspeed camera, show that the nucleation process is oddly non-uniform: the first vapor bubbles are always generated on the upper side of the tube and lead to a first wall temperature drop. A further increase in the heat flux values results in an increased wall superheat until bubbles nucleation originates also on the lower side of the tube causing a second wall temperature drop. Finally, at higher heat input levels, the boiling process becomes uniformly distributed on the inner tube surface. This phenomenon occurred also after a $180^{\circ}$ rotation of the glass

\footnotetext{
${ }^{1}$ Corresponding author
} 
tube and, after a critical analysis of the potential origins, it remains presently unexplained. An evaluation of the heat transfer coefficients for low vapor quality regimes is finally presented.

\section{INTRODUCTION}

Characterizing two-phase heat transfer phenomena inside mini and micro flow boiling systems is fundamental to understand how to increase the cooling capability of modern heat transfer devices. The need of an increased cooling capability is due to the smaller size of the components and the consequent higher specific heat generation. The complex nature of twophase flows in mini and micro-channels needs still to be completely understood, as underlined by Thome [1,2], Celata [3], Harirchian and Garimella [4] and recently reviewed by Baldassari and Marengo [5]. After more than 30 years, flow patterns, void fraction measurement, heat transfer coefficient evaluation, onset of nucleate boiling are still open research topics for the flow boiling in mini and microchannels [5,6]. Focusing on the ONB, which marks the boundary between the single-phase and two-phase heat transfer region, Ghiaasiaan et al. [7] developed a semi-empirical method for the estimation of the incipient boiling heat flux. Bang et al. [8] performed a digital photographic study of subcooled flow boiling to observe nearwall structures, giving primary attention to bubble formation and bubble coalescence in the bubble layer. Callizo et al. [9] presented boiling curves for R-134a and a comparison between the experimental heat transfer coefficients and the predictions from classical correlations. Liu et al. [10] investigated experimentally ONB of water in a rectangular micro-channel developing an analytical model able to predict the heat flux and the bubble size at the onset of boiling. Recently, Hong et al. [11] found that the heat flux and wall superheat needed to initiate the nucleate boiling in narrow rectangular channel under static conditions, increased with the mass flux and the inlet subcooling.

The present paper focuses on the experimental analysis of the heterogeneous onset of nucleate flow boiling of R-134a in a mini-channel having $4 \mathrm{~mm}$ internal diameter, with a particular non symmetrical physical outcome, which is making the present research inspiring further investigations. In fact the use of a transparent glass tube with transparent heaters allows the visualization of the ONB and evidences a gradual activation of the nucleation sites, starting from the upper side of the heater to the lower side, for all the tested mass flux. The corresponding boiling curves evidence two different temperature drops, associated to the starting of the nucleation from the upper side and from the lower side of the heater, respectively. Two temperature drops have been also observed by Piasecka et al. [12] during 
their boiling investigation. They found a two-stepped phase of the boiling phenomenon, similar to a second kind hysteresis, characteristic of nucleate pool boiling on developed micro-surfaces. They could not associate this kind of non-uniform condition to the flow pattern observation, since their experimental test-rig was not able to capture the bubble formation. In the present paper, ONB is visualized and recorded by means of a high-speed camera thanks to the ITO heaters, whose transparency allows a full characterization of the earliest stages of the bubbles formation. Several boiling curves are presented at different mass flux levels, $G=50,80,100,115$ and $137 \mathrm{~kg} / \mathrm{m}^{2}$ s together with the flow pattern visualization. Finally the heat transfer coefficient is calculated as a function of the heat flux and of the wall superheat for each mass flux.

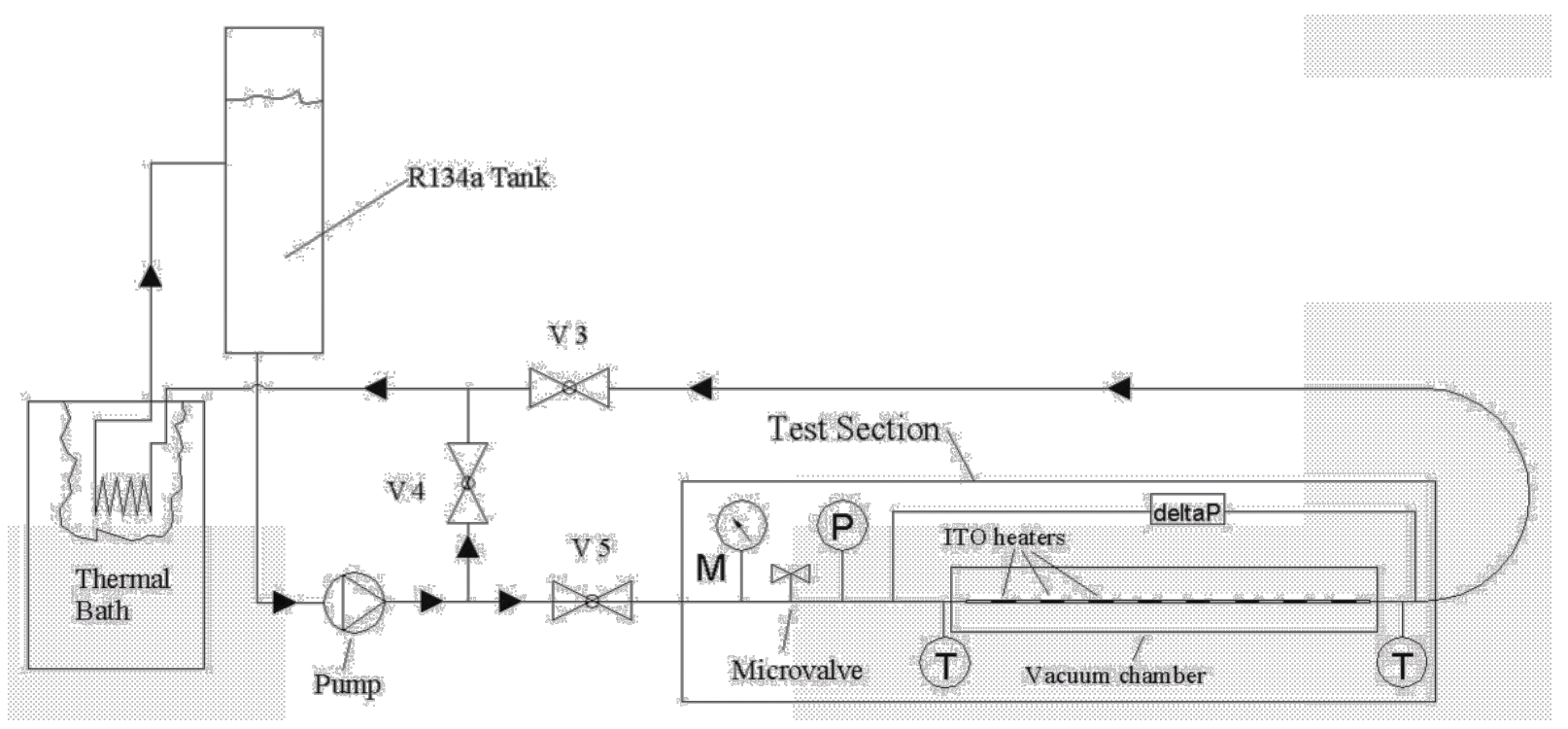

Figure 1 Experimental test rig scheme

\section{EXPERIMENTAL SET-UP AND PROCEDURE}

\subsection{Experimental set-up}

A schematic view of the experimental apparatus is given in Figure 1. The test section tube is made of high precision glass (DURAN) with an internal diameter of $4 \mathrm{~mm}$. The Eotvos number $E o=g\left(\rho_{L}-\rho_{V}\right) L^{2} / \sigma$ is hence set to 21.7 , i.e. the flow boiling process is studied in the so-called macroscale region. The transparent ITO film covers eight portions of equal length $(40 \mathrm{~mm})$ and each independent portion is used to electrically heat the glass surface allowing to observe and record the boiling mechanisms taking place inside the tube with a high speed $\mathrm{PCO}{ }^{\circledR}$ camera. The minichannel is enclosed in a co-axial glass tube with $60 \mathrm{~mm}$ external diameter vacuumed in order to eliminate the convection heat losses and consider only 


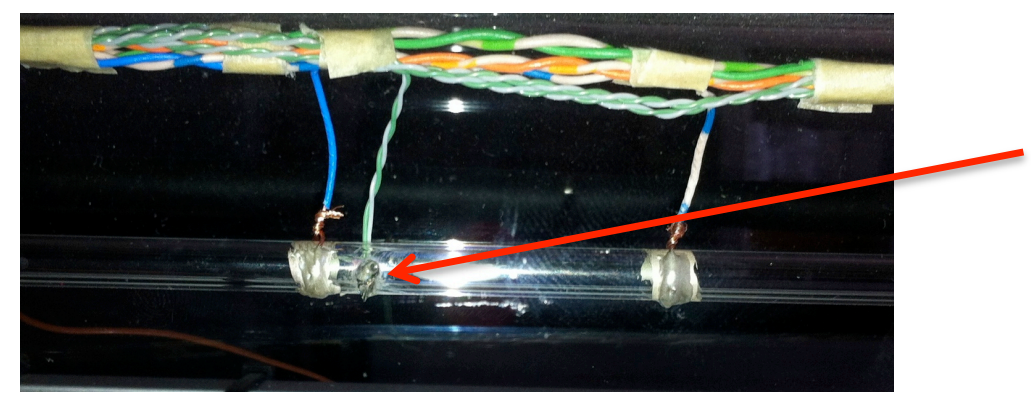
and at the middle of the tube height, as represented in Figure 2.
K-type thermocouple

\section{Figure 2 ITO heater and the position of the K-type thermocouple}

85

radiation losses. The temperature of the tube wall is monitored by means of eight K-type thermocouples $\left( \pm 0.2^{\circ} \mathrm{C}\right.$ after calibration) placed externally on each heater at the upstream side

During this experimental campaign one heater with a heat flux up to $30 \mathrm{~kW} / \mathrm{m}^{2}$ has been used. Refrigerant temperature is measured both at the test section inlet and outlet by two K-type thermocouples; the pressure is measured at the inlet by a PSE 510 pressure sensor.

The test rig consists of two main circuits: the test refrigerant loop and a secondary loop, where the fluid is thermally controlled. The loop is filled with R134a until the internal pressure reaches 6 bar, in order to bring the saturation temperature just below the ambient temperature. A helix type heat exchanger is cooled by means of a thermal bath HAAKE $\mathrm{C}^{2} 0 \mathrm{P}^{\circledR}$; this unit is necessary to define the operating experiment temperature and to condense the fluid coming from the test section in the form of wet vapor. The mass flow rate is measured by a Coriolis flow meter CORI-FLOW ${ }^{\circledR}$. ITO coatings power is controlled by the PC through the NI (National Instruments) USB- $6008^{\circledR}$ acquisition and control device and by the specifically designed electronic board, which is supplied with a 56V DC power supply. The electronic board applies the correct value of voltage to the heater in order to reach the desired electrical power and amplifies the coating voltage and current signals so that these can be acquired by the data acquisition module and transmitted to the PC. The radiation heat transfer between the ITO coating and the environment is numerically estimated and subtracted to the total power supplied to the ITO coatings in order to obtain the net thermal power supplied to the working fluid; this value is controlled with a standard PID (proportional-integral-derivative). Temperature and pressure signals are acquired using Agilent $34970 \mathrm{~A}^{\circledR}$. The system control, data acquisition software has been developed with Simulink ${ }^{\circledR}$ and dedicated MATLAB ${ }^{\circledR}$ 
106 programs have been developed for the data post processing. Other details on the test rig are 107 given in [13].

\subsection{Experimental procedure}

109 Before running the experiments, the coaxial glass chamber is vacuumed, the mass flux is 110 adjusted to the desired value, the fluid inlet temperature is set in order to enter the test section 111 in sub-cooled condition of maximum $2 \mathrm{~K}$, and the system works as close as possible to the 112 saturated boiling conditions. The heater power supply is set to the desired value which is 113 maintained until a steady tube temperature is reached. Mass flux, temperature, pressure and 114 power input values are stored using the data acquisition system. In order to define the 115 characteristic boiling curves, the power supplied to the fluid is increased, starting from $0 \mathrm{~W}$, 116 with increments of $0.5 \mathrm{~W}$ in the regions near the onset of nucleate boiling, and of $1 \mathrm{~W}$ in the 117 other regions until the maximum power $\left(\mathrm{Q}_{\max }=11 \mathrm{~W}\right)$. Then the power level is decreased 118 from the maximum value to $0 \mathrm{~W}$ with step of $1 \mathrm{~W}$. For each heat flux step, the corresponding

119 flow pattern is visualized and recorded using the high-speed camera. In order to provide the 120 necessary amount of light, a incandescent lamp is positioned in front of the camera. Because 121 the lamp temperature is very high, a glass covered with an infrared filtering film has been 122 located between the lamp and the test section, in order to minimize the radiated power.

123 The experimental procedure explained above is repeated two times for every mass flux value 124 examined, namely $\mathrm{G}=50 \mathrm{~kg} / \mathrm{m}^{2} \mathrm{~s}, \mathrm{G}=80 \mathrm{~kg} / \mathrm{m}^{2} \mathrm{~s}, \mathrm{G}=100 \mathrm{~kg} / \mathrm{m}^{2} \mathrm{~s}, \mathrm{G}=115 \mathrm{~kg} / \mathrm{m}^{2} \mathrm{~s}$ and $\mathrm{G}=$ $125137 \mathrm{~kg} / \mathrm{m}^{2} \mathrm{~s}$ in order to check the repeatability. Finally the temperature difference, usually 126 called wall superheat, is calculated for each heat input level:

$127 \Delta T_{\text {sh }}=T_{\text {win }}-T_{\text {sat }}$

128 where $\mathrm{T}_{\mathrm{w} \text {,in }}$ is the internal temperature of the heated wall, and it is calculated starting from the 129 temperature of the external surface of the mini-channel measured by the single K-type 130 thermocouple in Figure 2, considering the heat conduction through the glass. $T_{\text {sat }}$ is the fluid 131 inlet saturation temperature estimated with the help of the NIST REFPROP libraries [14], 132 knowing the fluid inlet pressure measured by the pressure sensor. Regarding the experimental 133 errors, the mass flow rate accuracy is $\pm 1 \%$ while the pressure accuracy is $\pm 0.5 \%$ in the 134 pressure range of $\mathrm{R}-134 \mathrm{a}$ experiments $(\approx 5.6 \mathrm{bar})$. The thermocouples have an accuracy of \pm $1350.2^{\circ} \mathrm{C}$ after calibration.

\section{EXPERIMENTAL RESULTS}


137 Thanks to the transparency of the ITO heaters, it is possible to visualize the earliest stages of 138 the bubbles formation and the phase transition phenomena (Figure 3 and 4). The flow patterns visualization reveals that the first nucleation event always appears on the upper side of the

140 heated tube for all the mass fluxes tested. Only after a further increase of the heat flux, the 141 nucleation starts also on the lower side of the heated tube. When the nucleation appears, it is 142 associated to a temperature drop. Hence the boiling curves presented in the next section 143 evidence two temperature drops, that are respectively associated to the upper side and to the 144 lower side onset of nucleate boiling.

145 The dimensionless numbers relative to the experimental conditions of Table 1 are given in 146 Table 2.

\begin{tabular}{|c|c|c|c|c|c|}
\hline Refrigerant & $\begin{array}{c}\text { Inlet pressure } \\
{[\mathbf{M P a}]}\end{array}$ & $\begin{array}{c}\text { Tsat } \\
{\left[{ }^{\circ} \mathbf{C}\right]}\end{array}$ & $\begin{array}{c}\text { G range } \\
{\left[\mathbf{k g} / \mathbf{m}^{2} \mathbf{s}\right]}\end{array}$ & $\begin{array}{c}\mathbf{q}^{\mathbf{\prime}} \\
{\left[\mathbf{k W} / \mathbf{m}^{\mathbf{2}}\right]}\end{array}$ & $\mathbf{x}[-]$ \\
\hline $\mathrm{R}-134 \mathrm{a}$ & $0.537-0.590$ & $18-21$ & $50-137$ & $0-22$ & $\max$ \\
\hline
\end{tabular}

147 Table 1 Summary of the experimental conditions

\begin{tabular}{|r|l|l|l|l|l|}
\hline $\begin{array}{l}\text { Specific } \\
\text { mass } \\
\text { flow rate }\end{array}$ & $\begin{array}{l}\text { Liquid phase } \\
\text { Capillary } \\
\text { number }\end{array}$ & $\begin{array}{l}\text { Liquid phase } \\
\text { Reynolds } \\
\text { number }\end{array}$ & $\begin{array}{l}\text { Vapor phase } \\
\text { Reynolds } \\
\text { number }\end{array}$ & $\begin{array}{l}\text { Boiling } \\
\text { number }\end{array}$ & Confinement number \\
\hline $\mathrm{G}$ & $\mathrm{Ca}(\mathrm{LO})$ & $\mathrm{Re}(\mathrm{LO})$ & $\mathrm{Re}(\mathrm{VO})$ & $\mathrm{Bl}$ & $\mathrm{Cn}$ \\
\hline$\left[\mathrm{kg} / \mathrm{m}^{2} \mathrm{~s}\right]$ & $C a_{L O}=\frac{\mu_{L} G}{\rho_{L} \sigma}$ & $\mathrm{Re}_{L O}=\frac{G d_{h}}{\mu_{L}}$ & $\mathrm{Re}_{V O}=\frac{G d_{h}}{\mu_{V}}$ & $B l=\frac{q^{\prime \prime}}{G h_{f g}}$ & $C n=\left[\frac{1-x}{x}\right]^{0.9} \cdot\left[\frac{\rho_{V}}{\rho_{L}}\right]^{0.5}$ \\
\hline 50 & 0.00097 & 975 & 17357 & 0.0024 & 1.161 \\
\hline 80 & 0.00156 & 1560 & 27771 & 0.0015 & 1.479 \\
\hline 100 & 0.00194 & 1949 & 34713 & 0.0012 & 1.803 \\
\hline 115 & 0.00223 & 2242 & 39920 & 0.0011 & 2.155 \\
\hline 137 & 0.00266 & 2671 & 47557 & 0.0009 & 3.023 \\
\hline
\end{tabular}

Table 2 The dimensionless number values for the experimental conditions

\subsection{Boiling curves and flow patterns}

150 The heat flux versus $\Delta \mathrm{T}_{\text {sh }}$ represents the boiling curve obtained during the experiments. In 151 Figure 3 and 4 the boiling curves and the flow patterns corresponding to $\mathrm{G}=115 \mathrm{~kg} / \mathrm{m}^{2} \mathrm{~s}$ and $152 \mathrm{G}=137 \mathrm{~kg} / \mathrm{m}^{2} \mathrm{~s}$ are presented. The red line corresponds to the increasing in the heat flux, 153 while the green line to the heat power decreasing. The boiling curves and the flow patterns 154 corresponding to the other mass fluxes tested in this paper are presented in [15]. 


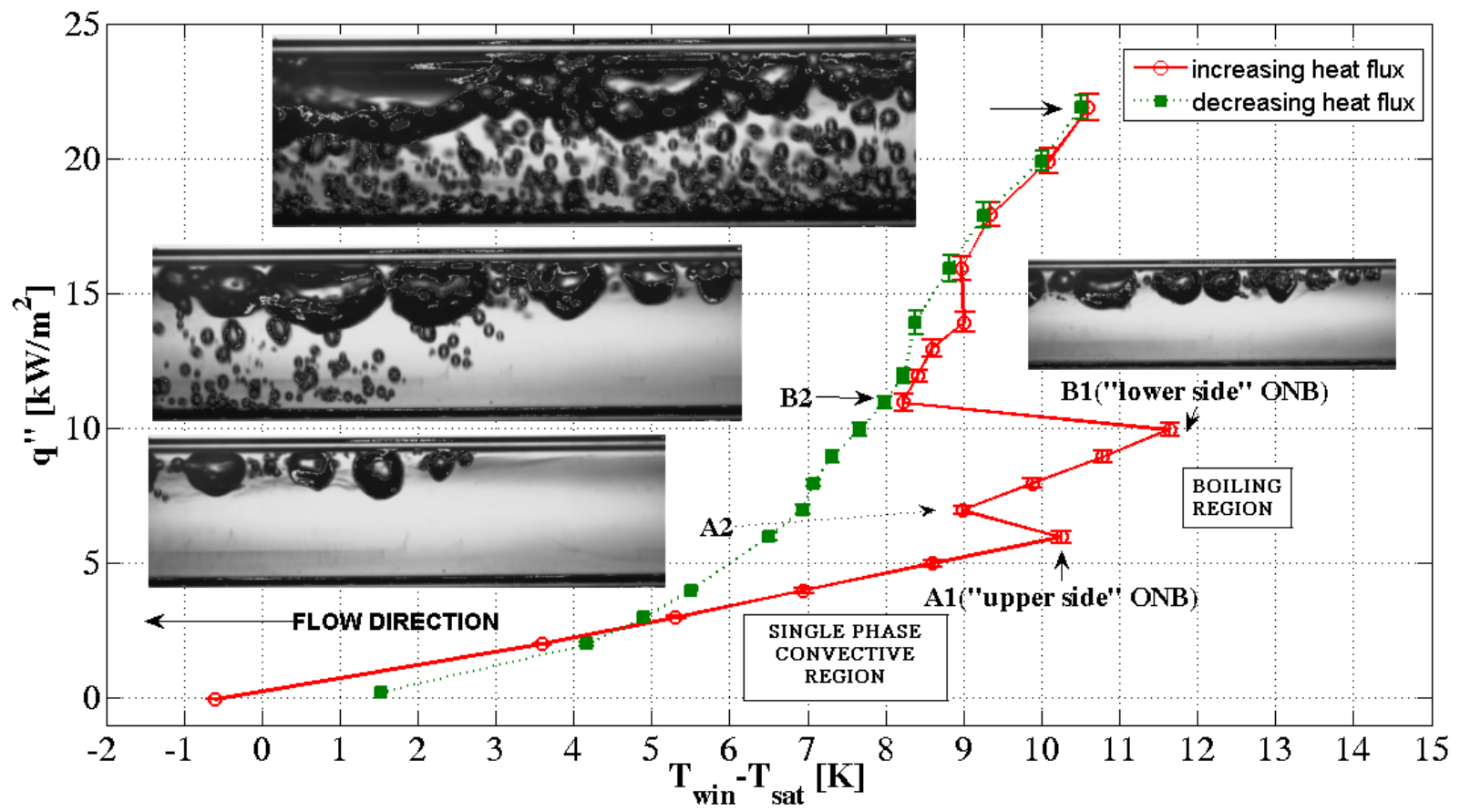

156 Figure 3 Boiling curve and flow patterns associated to points $\mathbf{A 2}, \mathbf{B 1}, \mathbf{B 2}$ and to q" $=22$ $\mathrm{kW} / \mathrm{m}^{2}$ for $\mathrm{G}=115 \mathrm{~kg} / \mathrm{m}^{2} \mathrm{~s}$ and a maximum vapor quality of 0.04 .

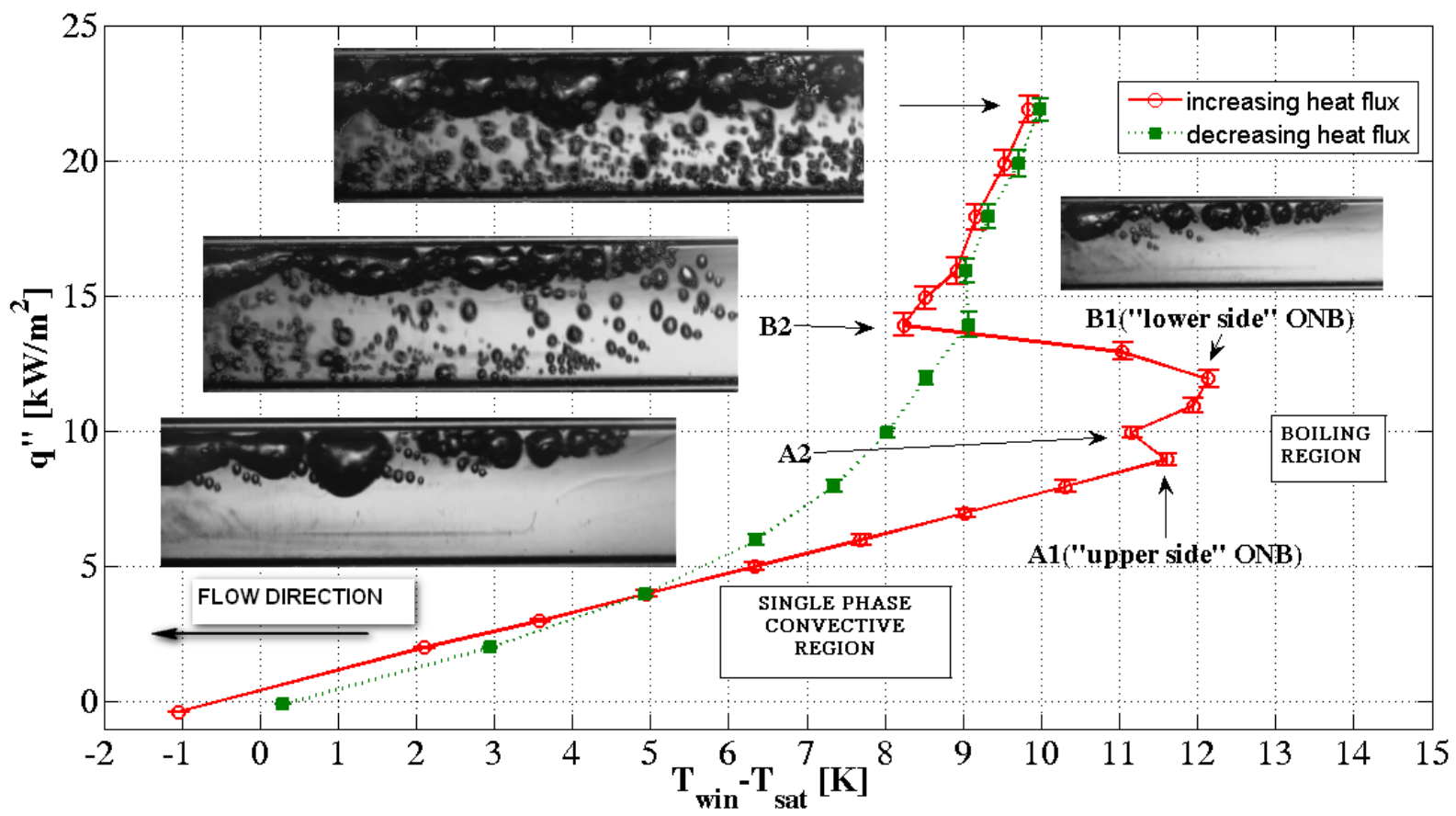

159 Figure 4 Boiling curve and flow patterns associated to points $\mathrm{A2}, \mathrm{B1}, \mathrm{B2}$ and to $\mathrm{q}^{\prime \prime}=22$ $160 \mathbf{k W} / \mathbf{m}^{2}$ for $\mathbf{G}=137 \mathbf{~ k g} / \mathrm{m}^{2} \mathbf{s}$ and a maximum vapor quality of 0.035 .

161 As usual, the values of wall superheat during the increasing of the heat flux are different from

162 those obtained during the heat flux reduction ("boiling hysteresis"). Two main regions, 
namely single phase forced convective region and boiling flow region, are clearly identified in

164 the figures above. Regarding the red lines in Figure 3 and 4, the heat flux increases almost linearly with the increasing in the wall superheat in the single phase convective region. The liquid refrigerant in contact with the tube internal surface soon becomes superheated, whereas the fluid bulk may remain saturated or even slightly subcooled. Further increase in the heat flux results in an increased wall superheat; vapor nuclei are activated and the boiling process occurs in the upper side of the tube. The ONB heat transfer mechanism causes the heating surface temperature to drop, resulting in a reduction of the wall temperature (A2 in Figure 3 and 4). A further increase of the heat flux results in an increase of the number of bubble sites and the wall superheat is again slowly increasing. In our experiment however a second temperature drop is clearly recognizable. From the visualizations it is possible to enlighten that this second temperature drop occurs when the nucleation starts also in the lower side of the heater. Hence such temperature drop (B2 in Figure 3 and 4) is due to a heterogeneous but non-uniform flow boiling process. In order to further clarify the nomenclature A1, A2, B1, B2 used in the figures above, it is important to define:

179 - A1 as the "upper side" ONB point; it corresponds to the maximum heat flux value at which 180 only liquid phase exists;

181 - A2 corresponds to the maximum temperature drop occurring after A1. Then a further

182 increase of the heat input level results in an increase of wall superheat;

183 - B1 is the "lower side" ONB, defined as the maximum wall superheat below which boiling is 184 still only activated in the upper side of the heater.

185 - B2 corresponds to the maximum temperature drop occurring after B1.

186 In B2 the nucleation starts also in the lower part of the heater. Afterwards boiling occurs more 187 uniformly on both the upper and lower tube surfaces, and the red curve is showing a more 188 regular trend, since the wall superheat increases almost linearly with the heat flux.

\subsection{Hypothesis on the origins of non-uniform onset nucleate boiling}

190 Four hypotheses were made by the authors to explain why in our experiment the nucleation 191 always starts in the upper side of the heater:

192 - the hydrostatic difference of pressure between the upper side and the lower side of the heater

193 could cause a difference in saturation temperature, which could be responsible for the non194 uniform boiling;

195 - a different surface roughness of the glass tube could influence the nucleation process; 
- the ITO coating could have been spattered with a non homogeneous thickness.

197 We have then achieved the following answers:

198 - the hydrostatic difference of pressure in a channel having $4 \mathrm{~mm}$ internal diameter at $20^{\circ} \mathrm{C}$ is

199 forty times lower than the pressure needed to increase the saturation temperature of $1^{\circ} \mathrm{C}$;

200 - the surface roughness of the glass is in the order of the nanometers and no scratch or defect

201 is optically noticeable on the surface at least at the microscale;

202 - the "upper side" and the "lower side" ONB were observed repeating the experiment using all 203 eight different ITO heaters in different positions along the tube;

204 - since the plasma coating procedure can originate the same non-uniformity for all the 8 205 heaters, the experiment was then repeated after rotating the tube of $180^{\circ}$. It was confirmed 206 that the boiling always starts in the upper side of the heater.

207 Additionally the low thermal diffusivity of the glass, used for the tubes, is of course 208 amplifying the effects of the non-uniform distribution of nucleation sites, since the internal 209 wall conduction is not able to reduce thermal gradients.

210 A possible temperature gradient inside the refrigerant flow could be a reason for such 211 phenomenon, even if the inlet of the minichannel is at least $600 \mathrm{~mm}\left(150 \mathrm{D}_{\mathrm{i}}\right)$ far from the last 212 geometrical change of the tube, which occurs just after the Coriolis flow meter, named $\mathrm{M}$ in 213 Figure 1.

214 A further possibility to explore is that, because of the presence of gas inside the refrigerant, a 215 number of gas molecules will accumulate in form of nanobubbles on the inner tube surface $216[16,17,18]$. The presence of gas inside the refrigerant, according to the standard Ahri 700217 2011, can be estimated as 1,5\% vol at $298 \mathrm{~K}$. Due to buoyancy forces the number of the 218 nanobubbles will be higher on the top side with respect to the bottom side. These pre-existing 219 air embryos entrapped in the flow and concentrated in the upper side of the mini-channel 220 could be the responsible for the starting of the nucleation on the upper side.

\subsection{Heat transfer coefficients}

222 From each boiling curve obtained decreasing the heat flux, it was possible to calculate the heat transfer coefficient according to the equation:

$\mathrm{q}^{\prime \prime}=\mathrm{h}\left(\mathrm{T}_{\mathrm{win}}-\mathrm{T}_{\text {sat }}\right)$

227 In Figures 5-7 the heat transfer coefficients are presented with the error bars; the uncertainties 228 are calculated according to the theory of error propagation, starting from the errors on the heat 
229 flux and on the wall superheat. In Table 3 the sensor accuracy and the estimated uncertainties 230 of the derived quantities are summarized.

231

\begin{tabular}{|c|c|c|c|}
\hline Sensors accuracy & Mass flow rate & $\begin{array}{c}\text { Pressure } \\
\text { (at } \approx 5.6 \text { bar })\end{array}$ & $\begin{array}{c}\text { K-type thermocouples } \\
\text { (after calibration) }\end{array}$ \\
\cline { 2 - 4 } & $\pm 1 \%$ & $\pm 0.5 \%$ & $\pm 0.2^{\circ} \mathrm{C}$ \\
\hline $\begin{array}{c}\text { Maximum } \\
\text { estimated uncertainty }\end{array}$ & Heat flux & Wall superheat & $\begin{array}{c}\text { Heat transfer } \\
\text { coefficient }\end{array}$ \\
\cline { 2 - 4 } & $\pm 4 \%$ & $\pm 7 \%$ & $\pm 8 \%$ \\
\hline
\end{tabular}

233 quantities

234 Boiling curves and the associated flow patterns for $G=50,80$ and $100 \mathrm{~kg} / \mathrm{m}^{2} \mathrm{~s}$ are presented 235 in [15]. It is important to point out that the data obtained for $G=50 \mathrm{~kg} / \mathrm{m}^{2} \mathrm{~s}$ have the 236 peculiarity that phase A1 may not correspond only to a single liquid phase, since first 237 nucleation events may occurs even before, without a measurable variation of the wall 238 superheat. This effect is due to the fact that a single thermocouple for each heater is not able 239 to capture the local temperature variation around the bubble nucleation site. Such 240 measurement weakness may produce larger experimental inaccuracies, even with the current 241 high precision, especially for low wall superheat temperatures. 


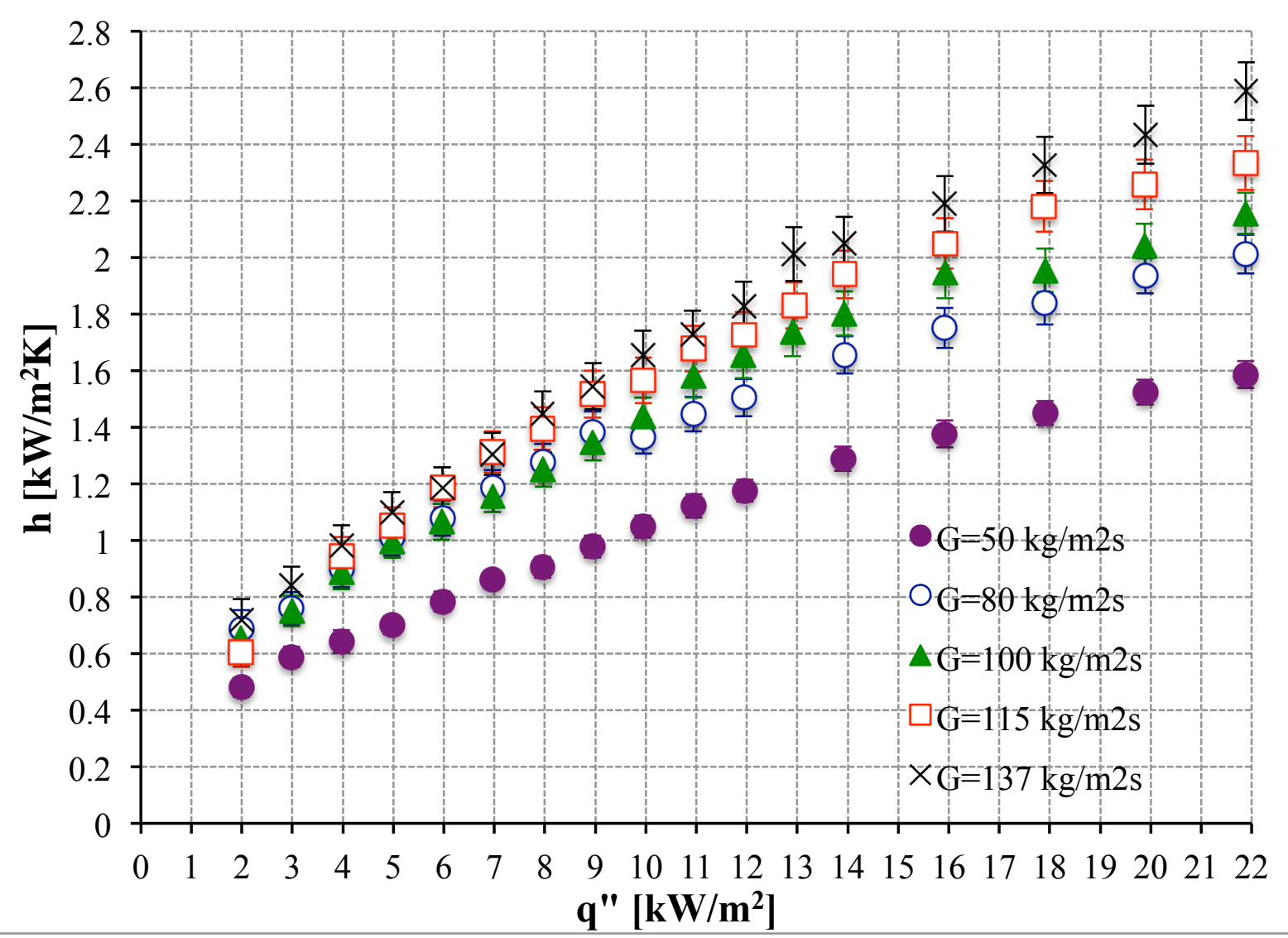

Figure 5 The heat transfer coefficient $h$, evaluated from each boiling curve - obtained decreasing the heat flux - as function of the heat flux.

245 In Figure 5 for a heat flux about $9 \mathrm{~kW} / \mathrm{m}^{2}$ the data obtained with $\mathrm{G}=100 \mathrm{~kg} / \mathrm{m}^{2} \mathrm{~s}$ apparently decrease more than the data with $\mathrm{G}=80 \mathrm{~kg} / \mathrm{m}^{2}$ s, keeping lower values until the minimum heat

247 flux of $2 \mathrm{~kW} / \mathrm{m}^{2}$ is reached. Such a trend inversion is explained considering only the 248 experimental accuracy, since there is no relevant change in the flow patterns. 


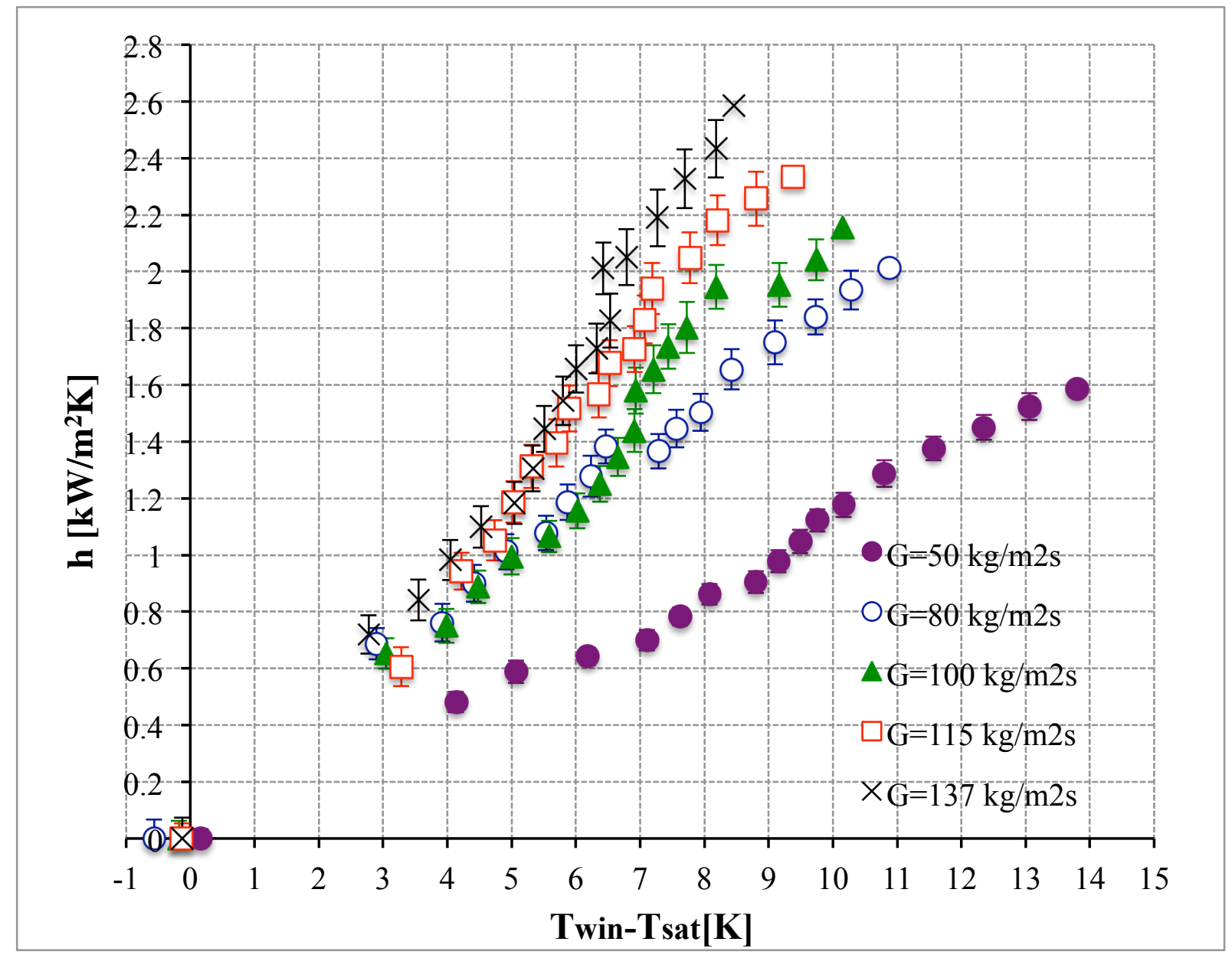

251 Figure 6 The heat transfer coefficient $h$, calculated from each boiling curve - obtained 252 decreasing the heat flux - as function of the wall superheat. 


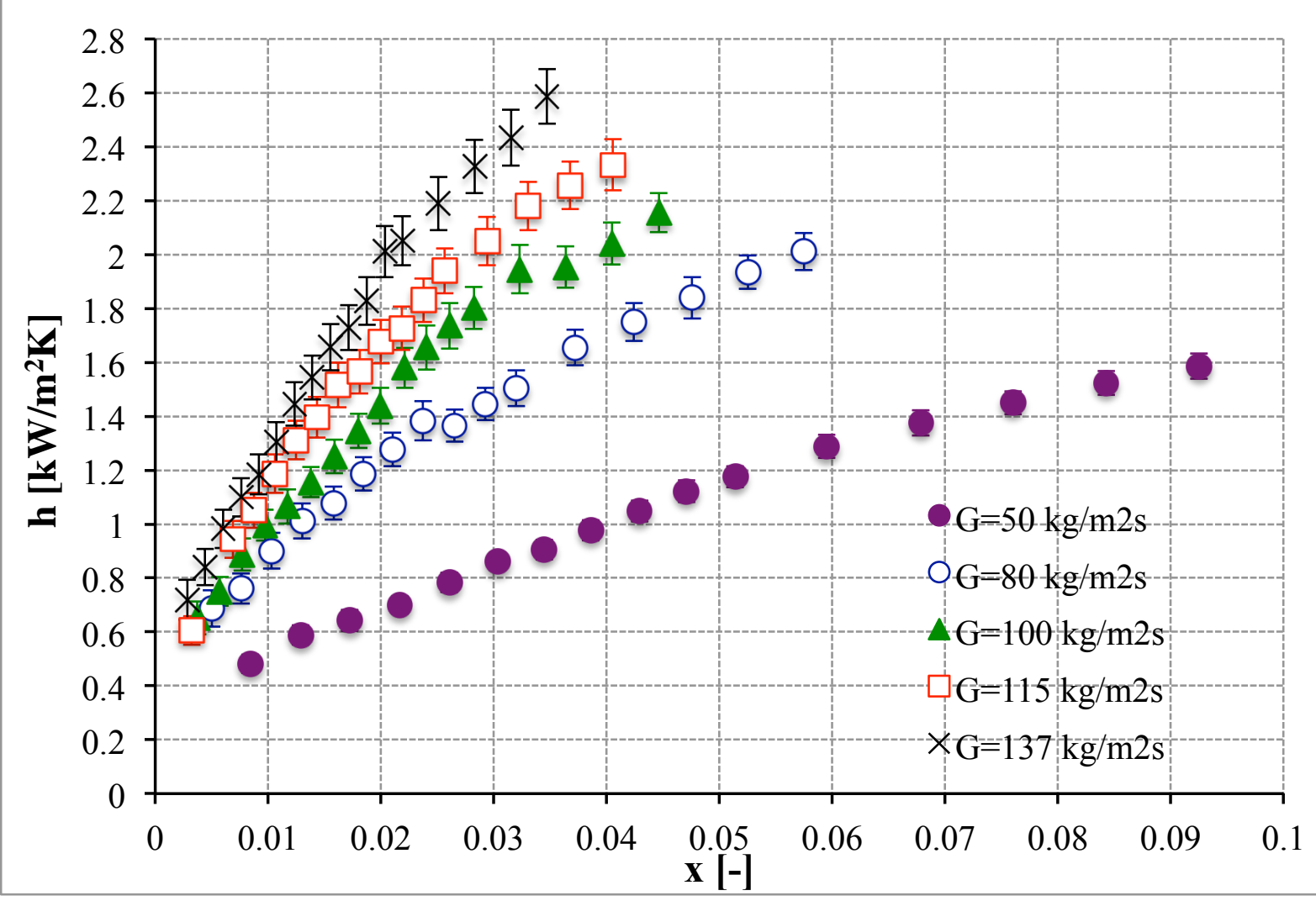

254 Figure 7 The heat transfer coefficient $\mathbf{h}$, calculated from each boiling curve - obtained 255 decreasing the heat flux - as function of the vapor quality.

256 The heat transfer coefficient, estimated at one fixed heat flux value or one wall superheat 257 value, increases with the mass flux level. For such very low vapor qualities, the heat transfer coefficient increases with the vapor quality, meaning that more active bubbling (in terms of 259 frequency and nucleation site density) is increasing the heat transfer from the wall. Note that 260 this appears to be in contrast with many experimental studies, among which [19,20,21], which 261 predict a decrease of the heat transfer coefficient with vapor quality.

262 A final important consideration is related to the comparison of the obtained heat transfer 263 coefficient values with some common correlations of the literature, summarized in table 4, 264 which are given in Figure 8 a,b,c. 


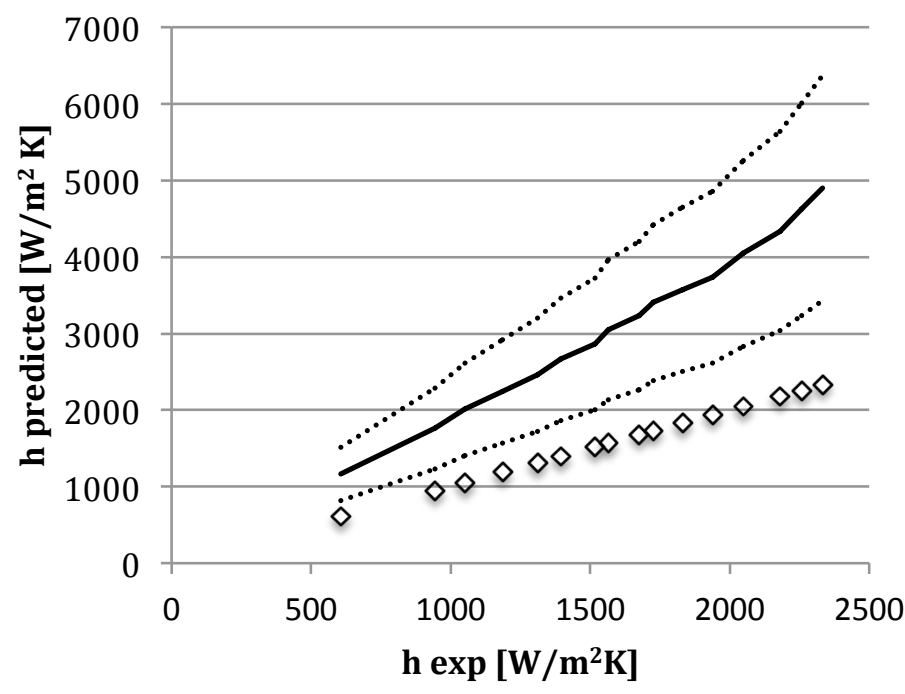

$\diamond \mathrm{h} \exp [\mathrm{W} / \mathrm{m} 2 \mathrm{~K}]$

— $\mathrm{h}$ Tran et al.1996 [W/ $\mathrm{m} 2 \mathrm{~K}]$ $30 \%$

266 (a)

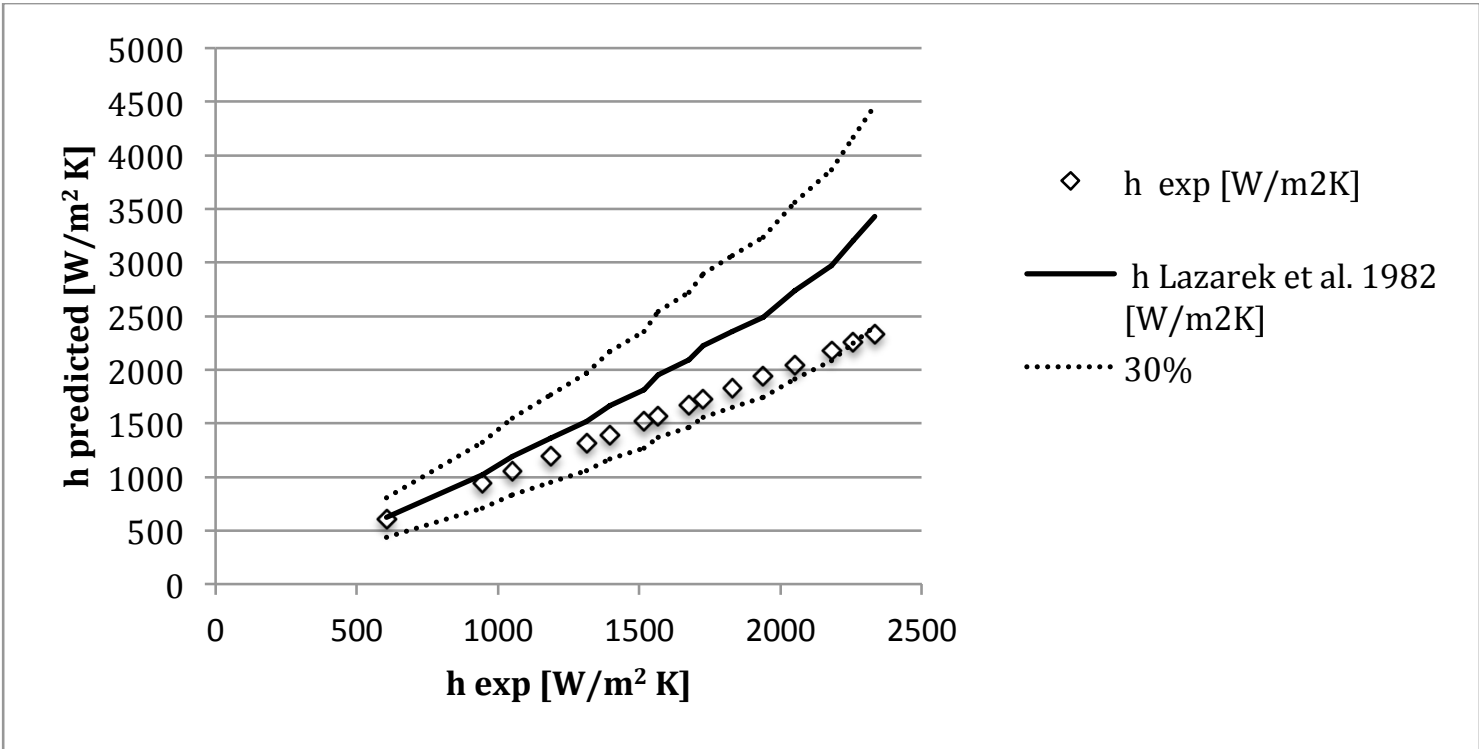

268

(b) 


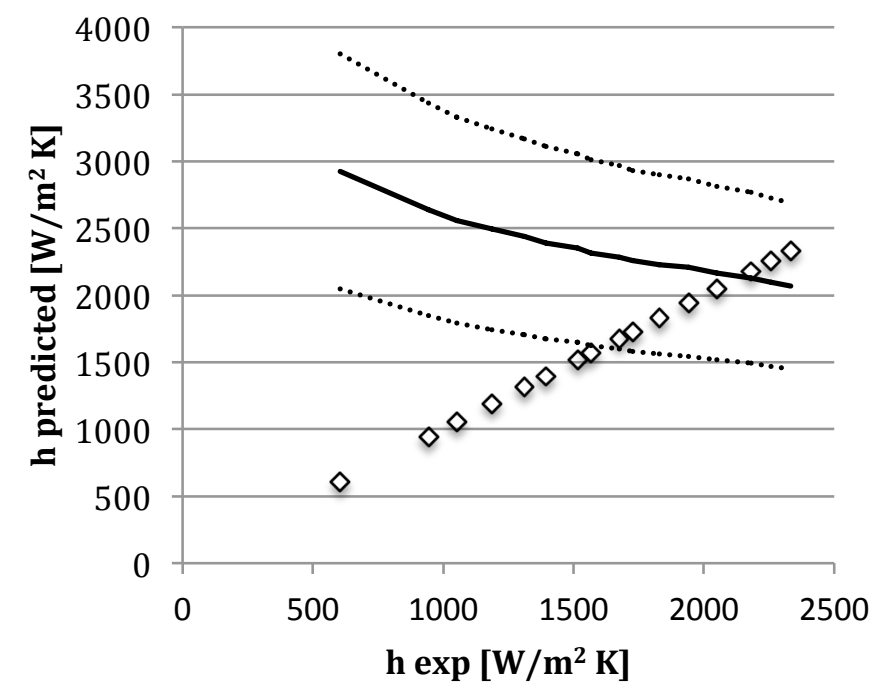

$\diamond \mathrm{h} \exp [\mathrm{W} / \mathrm{m} 2 \mathrm{~K}]$

- $\mathrm{h}$ Lee and Mudawar 2005 $[\mathrm{W} / \mathrm{m} 2 \mathrm{~K}]$ $30 \%$

(c)

Figure 8 Comparison of the heat transfer coefficients, calculated from the experimental boiling curve decreasing the heat flux $\left(G=115 \mathrm{~kg} / \mathrm{m}^{2} \mathrm{~s}\right.$, vapor quality range $0<x<0.04$, open symbols) with standard correlations in literature summarized in Table 4 (lines).

\begin{tabular}{|l|l|}
\hline Name of the correlation & Equation and experimental range \\
\hline Lazarek and Black [23] & $h=\left(30 \mathrm{Re}_{L O}^{0.857} B l^{0.714}\right) \frac{k_{L}}{d_{h}} \mathrm{R}-113$ \\
& $14<\mathrm{q}^{\prime \prime}<380 \mathrm{~kW} / \mathrm{m}^{2} 125<\mathrm{G}<750 \mathrm{~kg} / \mathrm{m}^{2} \mathrm{~s} 0<\mathrm{x}<0.6$ \\
\hline Tran et al. [22] & $h=8.4 \cdot 10^{5} \cdot\left(W e_{L O} B l^{2}\right)^{0.3}\left(\frac{\rho_{L}}{\rho_{V}}\right)^{-0.4} \quad \mathrm{R}-12$ \\
& $3.6<\mathrm{q}^{\prime \prime}<129 \mathrm{~kW} / \mathrm{m}^{2} 44<\mathrm{G}<832 \mathrm{~kg} / \mathrm{m}^{2} \mathrm{~s} 0<\mathrm{x}<0.94$ \\
\hline Lee and Mudawar [24] & $h=3.856 X^{0.267} h_{L}$ for $\mathrm{x}<0.05$ \\
& $\mathrm{R}-134 \mathrm{a}, 159<\mathrm{q}^{\prime \prime}<938 \mathrm{~kW} / \mathrm{m}^{2} 127<\mathrm{G}<654 \mathrm{~kg} / \mathrm{m}^{2} \mathrm{~s}$ \\
\hline
\end{tabular}

Table 4 The empirical correlations of Lazarek and Black [23], Tran et al [22] and Lee and Mudawar [24]

276 The correlations of Lazarek and Black [23] and Tran et al. [22] do not contain the vapor

277 quality parameter. Therefore, since the present experiments have been done in a narrow range 278 of vapor qualities, the correlation of Lee and Mudawar [24] was also considered. They 279 proposed a correlation for the heat transfer coefficient for R-134a and water in three ranges of 
vapor quality: $\mathrm{x}<0.05,0.05<\mathrm{x}<0.55,0.55<\mathrm{x}<1$. The correlation for vapor quality lower than 0.05 was implemented in the comparison even if the heat flux range for such correlation is higher than $22 \mathrm{~kW} / \mathrm{m}^{2}$ (Figure 8). The heat transfer coefficient $\mathrm{h}_{\mathrm{L}}$ for the liquid phase was calculated according to Shah correlation [25].

The measured heat transfer coefficient values are in good agreement with the correlation of Lazarek et al. [22], with larger deviations with respect to the correlation of Tran et al. [23], while a strong departure with the correlation of Lee and Mudawar [24] appears. This correlation, for vapor quality lower than 0.05 , was in fact validated only for water and none of the R-134a data. For a heat flux up to $22 \mathrm{~kW} / \mathrm{m}^{2}$, the values of the heat transfer coefficients are strictly related to the increase of bubble number and frequency. The estimated values of the heat transfer coefficient appear to be lower than expected, interpolating data for higher vapor quality values. The use of a single thermocouple on the minichannel and the fact that the glass has a low thermal conductivity, partially motivate the under-evaluation of the heat transfer coefficient.

\section{CONCLUSIONS}

Saturated heterogeneous non-uniform flow boiling of R134a in horizontal mini-channel has been experimentally investigated at five different mass flux levels (50, 80, 100, 115 and 137 $\mathrm{kg} / \mathrm{m}^{2} \mathrm{~s}$ ) with particular attention on the visualization of the onset of nucleate boiling. The boiling curves evidence two different temperature drops and this is due to the fact that nucleation always starts in the upper side of the heaters and only increasing the heat flux, activating more nucleation sites, boiling starts later in the lower part of the heater. The flow pattern visualizations highlight this non-uniform boiling. The reason for such behavior is still under investigation and it should be also linked to the low thermal diffusivity of the glass, which is rarely used in flow boiling studies as tube material. The heat transfer coefficient has been estimated as function of the heat flux and of the wall superheat for all tested mass fluxes. It emerges that, as expected, the heat transfer coefficient values, estimated at a fixed heat flux value or wall superheat value, increases with the mass flux level. With such very low vapor quality values, the heat transfer coefficients appear to increase with the vapor quality, i.e. with the number and frequency of bubble detaching from the surface. The estimated values of the heat transfer coefficients are ranging from $500 \mathrm{~W} / \mathrm{m}^{2} \mathrm{~K}$ to $2000 \mathrm{~W} / \mathrm{m}^{2} \mathrm{~K}$, slightly less than expected values, obtained from previous standard empirical correlations. 


\section{NOMENCLATURE}

312 Bl Boiling number

$313 \mathrm{~d}_{\mathrm{h}}$ Hydraulic diameter, $\mathrm{m}$

$314 \mathrm{~h}$ Heat transfer coefficient, W/m $\mathrm{m}^{2} \mathrm{~K}$

$315 \mathrm{~h}_{\mathrm{L}}$ Heat transfer coefficient for the liquid phase, $\mathrm{W} / \mathrm{m}^{2} \mathrm{~K}$

$316 \mathrm{k}_{\mathrm{L}}$ Liquid thermal conductivity, $\mathrm{W} / \mathrm{mK}$

317 q" Heat flux, W/m²

$318 \mathrm{Q}_{\max }$ Maximum power supplied to the fluid, W

$319 \mathrm{Re}_{\mathrm{LO}}$ Reynolds number for total flow assumed as liquid

$320 \mathrm{~T}_{\text {win }}$ Internal temperature of the heated wall, $\mathrm{K}$

$321 \mathrm{~T}_{\text {sat }}$ Saturation temperature, $\mathrm{K}$

$322 \mathrm{We}_{\mathrm{LO}}$ Weber number for total flow assumed as liquid

$323 \times$ Vapour quality

324 X Martinelli parameter

$325 \Delta \mathrm{T}_{\mathrm{sh}}$ Wall superheat, $\mathrm{K}$

$326 \rho_{\mathrm{L}}$ Liquid density, $\mathrm{kg} / \mathrm{m}^{3}$

$327 \rho_{\mathrm{V}}$ Vapor density, $\mathrm{kg} / \mathrm{m}^{3}$

\section{ACKNOWLEDGEMENTS}

329 The work was financed by Italian Ministry of Universities through the project PRIN 2009 330 "Experimental and Numerical Analysis of Two-Phase Phenomena in Microchannel Flows for 331 Ground and Space Applications". We would like to acknowledge Dr. Stefano Dall'Olio for 332 the experimental set-up in Dalmine, Dr. Stefano Zinna and Eng. Antonello Cattide for the 333 help and the discussions.

\section{REFERENCES}

[1] J.R. Thome, Boiling in microchannels: a review of experiment and theory, Int. J. Heat Fluid Flow, 25, 128-139, 2004.

[2] J.R. Thome, State of the art overview of boiling and two-phase flows in microchannels. Heat Transfer Engineering, 27 (9), 4-19, 2006.

339 [3] G.P. Celata, Single and two-phase flow heat transer in micropipes. Proc. Symp. 5th European Thermal-Sciences Conference, The Nederlands. 2008. 
[4] T. Harirchian and S.V. Garimella, Boiling Heat Transfer and Flow Regimes in Microchannels- A Comprehensive Understanding, Journal of Electronic Packaging, 133 (1), 011001-1/10, 2001.

[5] C. Baldassari and M. Marengo, Flow boiling in microchannels and microgravity, Progress in Energy and Combustion Science, 39, 1-36, 2013.

[6] D.B. Tuckerman and R.F.W. Pease, High-Performance Heat Sinking for VLSI, IEEE Electron Device Lett., ELD-2(5), 126-129, 1981.

[7] S.M. Ghiaasiaan and R.C. Chedester, Boiling incipience in microchannels. Int. J. Heat Mass Transfer, 45, 4599-4606, 2002.

[8] C. Bang, S.H. Chang, W.P. Baek, Visualization of the subcooled flow boiling of R-134a in a vertical rectangular channel with an electrically heated wall. Int. J. of Heat and Mass Transfer, 47, 4349-4363, 2004.

[9] C.M. Callizo, B.P. Palm, W. Owhaib, Subcooled flow boiling of R-134a in vertical channels of small diameter. International Journal of Multiphase Flow, 33, 822- 832, 2007.

[10] D. Liu, P.S. Lee, S.V. Garimella, Prediction of the onset of nucleate boiling in microchannel flow. International Journal of Heat and Mass Transfer, 48, 5134-5149, 2005.

[11] G. Hong, X. Yan, Y.H. Yang, S. Liu, Y.P. Huang, Experimental study on onset of nucleate boiling in narrow rectangular channel under static and heaving conditions. Annals of Nuclear Energy , 39, 26-34, 2012.

[12] M. Piasecka, S. Hozejowska, M.E. Poniewski, Experimental evaluation of flow boiling incipience of subcooled fluid in a narrow channel, International Hournal of Heat and Fluid Flow, 25, 159-172, 2004.

[13] S. Dall'Olio, M. Marengo, Boiling of R134a inside a glass minichannel. A new statistical approach of flow pattern characterization based on flow visualization. Int. J. Heat Mass Transfer, 55, 1048-1065, 2012.

[14] E.W. Lemmon, M.L. Huber, M.O. McLinden, NIST Standard Reference Database 23:

Reference Fluid Thermodynamic and Transport Properties-REFPROP, Version 8.0, National Institute of Standards and Technology, Standard Reference Data Program, Gaithersburg 2007.

[15] C.Baldassari, M. Mameli, M. Marengo, Experimental Analysis Of Heterogeneous Non Uniform Flow Boiling Of R-134a Inside A Glass Minichannel, Proc. Symp. ECI 8th International Conference on Boiling and Condensation Heat Transfer, 2012 
[16] J.R.T. Seddon, H.J. Zandvliet, D. Lohse, Knudsen Gas Provides Nanobubble Stability, Phys. Rev. Lett., 107 (11), 116101, 2011.

[17] J.R.T. Seddon, E.S. Kooij, B. Poelsema, H.J. Zandvliet, D. Lohse, Surface Bubble Nucleation Stability, Phys. Rev. Lett. 106, 056101, 2011.

[18] C.U. Chan, C.D. Ohl, Surface Nanobubble Nucleation Visualized with TIRF Microscopy, arXiv:1204.2633, 2012.

[19] Wambsganss, M. W., France, D. M., Jendrzejczyk, J. A., Tran, T. N., Boiling Heat Transfer in a Horizontal Small-Diameter Tube, J. Heat Transfer, vol. 115, pp. 963-972, 1993.

[20] Lin, S., Kew, P. A., and Cornwell, K., Flow Boiling of Refrigerant R141B in Small Tubes, Trans IChemE 79, part A, pp. 417-424, 2001.

[21] Yen,T.-H., Kasagi, N., and Suzuki,Y., Forced Convective Boiling Heat Transfer in Microtubes at Low Mass and Heat Fluxes, Compact Heat Exchangers, A Festschrift on the 60th Birthday of Shah, R.K.. Eds. G. P. Celata, B. Thonon, A. Bontemps, and S. G. Kandlikar, Edizioni ETS, Pisa, Italy, 2002.

[22] Tran T.N., Wambsganss M.W., France D.M. Small circular- and rectangular channel boiling with two refrigerants. International Journal of Multiphase Flow; 22-3: pp.485-498, 1996.

[23] Lazarek G.M., Black S.H. Evaporative heat transfer, pressure drop and criticalheat flux in a small vertical tube with R-113. International Journal of Heat and Mass Transfer, 25-7: pp.945-960, 1982.

[24] Lee, H.J., Mudawar, I., Two-phase flow in high-heat-flux micro-channel heat sink for refrigeration cooling applications: Part II-heat transfer characteristics, Int. J Heat Mass Transfer, 48, pp.941-955, 2005.

[25] Shah M.M, A general correlation for heat transfer during film condensation inside of pipes, Int. J. Heat and Mass Transfer, Vol. 22, pp. 547-556, 1979. 